\title{
Thinking music in the web age (2)
}

The articles collected in the present issue of De Musica derive from contributions to the international conference "Penser la musique à l'ère du web / Thinking Music in the Web Age"1 and continue the investigation developed in the previous issue on the rapid and profound transformations of the contemporary musical culture in the web age. They deal in particular with the impact of the so-called digital revolution on the production, the distribution and the reception of music.

A first group of articles focuses on music production. New technologies, and in particular the recent developments in artificial intelligence and telematic communication, offer new tools for the creativity of performers and composers, beyond the usual acoustic and electronic instruments and beyond the possibilities offered by traditional notational systems based on written scores. On the one hand, new collaborative forms of music production are made possible by portable and very common devices, such as smartphones (Le Bouteiller), or by means of innovative software (Guesdon \& Le Guern); on the other hand, technologies amplify and renew creative possibilities, such as the compositional exploitation of sound archives (Cossettini) - a resource nowadays enhanced by the capillarity and lightning speed of distribution through the Internet - and improvisational practices, which can now be extended to interaction through computer networks and with computational performers (Bertinetto).

A second group of articles focuses on the recent changes characterizing the systems of music distribution and reception in the digital age. In a context now largely dominated by streaming platforms -that seem to have displaced sales strategies based on downloading -, it is interesting to reflect on the possible futures of record production, as in the case of CD or vinyl, a format

\footnotetext{
${ }^{1}$ See De Musica 24/2.
} 
that has experienced an unexpected renaissance (Lephay). It is also crucial to understand the ways in which these streaming platforms have helped to reshape the role of the music lover, as in the case of digital forms of opera fandom (Palazzetti) or with relation to the transformation of established social practices such as flânerie and collecting (Ruta). Finally, special consideration is given to emerging technologies based on "blockchains" (Magaudda), the advantages of which in terms of the organization of musical traces are not so obvious.

The rich and varied range of contributions discussed in this double issue of De Musica (24, II and 25, I) are far from exhausting the topic we have set out to explore. The aspects that would deserve greater attention are: first, the new forms of audiovisual production which characterize contemporary modalities of music distribution and which are increasingly destined to combine sound and images; second, the way in which digital technology fosters the emergence not only of new ways of music production, but also of new genres. Nonetheless we are confident that this first overview offers the reader important elements of information and reflection on the modifications of the production and distribution of music in the web age: for the last thirty years we have been immersed in a sort of "hypermedia" world, whose power has been drastically amplified by the recent pandemic. This which imposes a profound revision of the ways we think about music.

Alessandro Arbo and Alessandro Bertinetto 